\title{
Effect of Temperature and Vibration on Electrical Connectors with Different Number of Contact Cores
}

\author{
W. L. Song ${ }^{1}$, J. T. Li ${ }^{1}$, N. Wang ${ }^{1}$, Z. L. Sun ${ }^{1}$, M. J. Zhang ${ }^{2}$, Q. Yang ${ }^{1}$ \\ ${ }^{1}$ School of Mechanical Engineering and Automation, Northeastern University, Shenyang 110819, China \\ ${ }^{2}$ Shenyang Xinghua Aero-electric Appliance Limited Liability Company, Shenyang 110142, China
}

\begin{abstract}
In this paper, we presented the results from three related analysis performed by adopting the failure models, which provided an explanation of performance influencing factors caused by different number of contact cores, for the purpose of measuring the temperature change and deformation value, which were the factors causing contact failure. The failures were localized in contact parts of the connectors. Performed investigations included thermal analysis, modal analysis, harmonic response analysis and contact failure analysis. From the results of these simulations, related temperature and vibration analysis nephograms were got respectively. And the correctness of results of thermal analysis was verified by Fourier law. The research results of this paper provide a reference for thermal analysis and vibration analysis of electrical connectors, which is important for ensuring the reliability and safety of electrical connectors.
\end{abstract}

\section{Introduction}

The increase in the number of electronic and electric systems used in the aerospace industry necessitates a better performance for electrical connectors. The main failure mode is contact failure, and the temperature and vibration are the main reasons that determine the performance of electrical connectors, as under the action of environmental stress [1]. Both of the formation of fretting wear, the occurrence of transient fracture and the growth of oxide film, that caused by vibration and the oscillation of temperature will have adverse effects on the electrical connectors. Therefore, thermal analysis and vibration analysis of electrical connectors are necessary for meeting its performance.

Few related studies about contact failure of electrical connectors have been done. HAYASHI et al. [2] present that at least four contact points are necessary in order to decrease noise radiation from two independent experiments performed by adopting the Contact Failure Model. Hayashi et al. [3] study the effects of the contact distribution and the number of contact points on the common-mode current in the coaxial cable as well as on the current distribution among the contact points. LeFevre et al. [4] conduct two case studies for failure analysis of connector which provided a better understanding of the mechanisms for design and testing purposes. Zhou et al. [5] conduct a failure analysis for a kind of low power connector which adapted fretting simulation by vibrator, showed that connection resistance of connectors was raised up, even to ohms level.

However, the effect of temperature and vibration on the relationship between reliability and different cores of electrical connectors has not been reported.

The purpose of this work is to study the behavior of electrical connectors with different cores that used in the aerospace industry by basing on establishing three models with the same structure and dimension for the contact pin, insulator and shell, but with a different of number contact pins.

\section{Thermal analysis of electrical connector}

Thermal transmission results from the temperature difference between two objects or an object interior. The 
main thermal transmission mode of electrical connectors

convection formed from the shell exposed to air.

is internal thermal conduction, followed by the thermal

Table 1. Material and its parameters for electrical connectors.

\begin{tabular}{|c|c|c|c|c|c|}
\hline component & material & $\begin{array}{c}\text { thermal conductivity } \\
{\left[\mathrm{Wm}^{-1} \mathrm{~K}^{-1}\right]}\end{array}$ & $\begin{array}{c}\text { Specific heat } \\
\text { capacity } \\
{\left[\mathrm{kg} \mathrm{J}^{-1} \mathrm{~K}^{-1}\right]}\end{array}$ & $\begin{array}{c}\text { Elasticity modulus } \\
{[\mathrm{GPa}]}\end{array}$ & Poisson's ratio \\
\hline Contact body & brass & 122 & 380 & 106 & 0.324 \\
\hline Shell & constructional steel & 43.53 & 460 & 106 & 0.4 \\
\hline insulator & PTEF & 0.197 & 1.0 & 120 & 0.4 \\
\hline
\end{tabular}
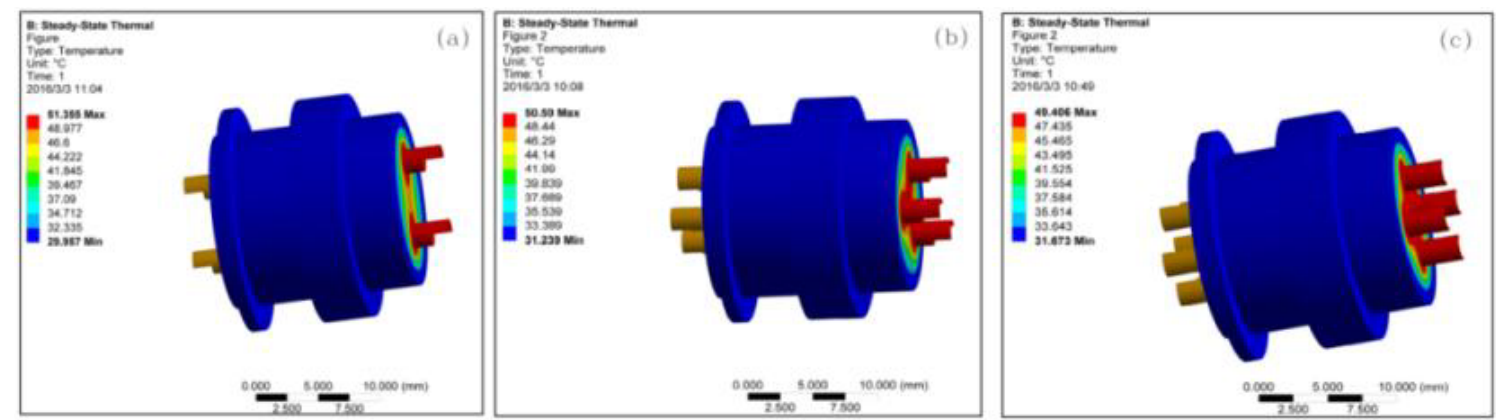

Figure 1. Temperature distribution ( $\mathrm{a}$ is for 2 cores, $\mathrm{b}$ is for 3 cores, $\mathrm{c}$ is for 4 cores).

For steady-state thermal analysis, material property-thermal conductivity is only required. Set material properties as showed in Table 1 after the three models imported in Workbench ANSYS.

The working state of $25{ }^{\circ} \mathrm{C}$ is set for steady state thermal analysis of electrical connectors. The natural convection coefficient is $5.78\left[\mathrm{w} /\left(\mathrm{m}^{2} \cdot{ }^{\circ} \mathrm{C}\right)\right]$, which is applied to the shell by the contact body with the rated current of $15 \mathrm{~A}$, and the steady-state temperature distribution diagrams of the models are obtained showed in Fig. 1 (a), (b) and (c) respectively.

Transient thermal analysis with analysis time and time step set to $45 \mathrm{~s}$ and $5 \mathrm{~s}$ is conducted on the basis of steady state thermal analysis. When the internal heat generation load is applied, the transient maximum temperature of the models can be obtained by loading the load applied to the steady state analysis.

Fig. 1 clearly shows the steady-state temperature field distribution of electrical connectors. Computational results of temperature field distribution show that high temperature concentration existed at the root of core inserts and the shell near the cores. The maximum temperatures of model I, II and III are $51.36{ }^{\circ} \mathrm{C}, 50.59{ }^{\circ} \mathrm{C}$ and $49.40{ }^{\circ} \mathrm{C}$ respectively show that with the increase of the number of cores, the maximum temperature shows a decreasing trend.

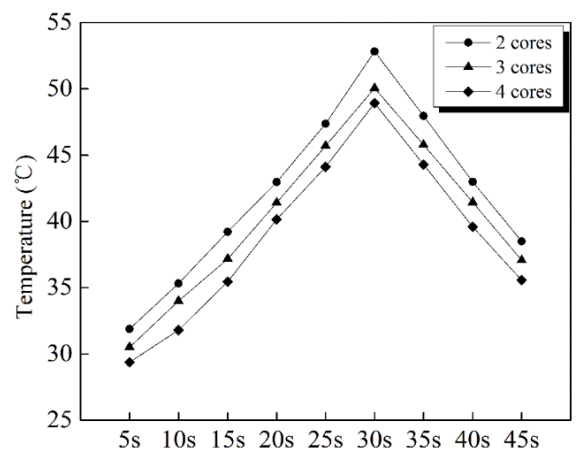

Figure 2. Maximum temperature (transient state).

Fig. 2 shows the transient temperature of the three models respectively. Observe carefully, the temperature of model I and II are higher than that of the model II and III respectively in every period of time, shows that with the core insert added, the heat dissipation performs better and better, which is consistent with the conclusion of steady state thermal analysis.

\section{Vibration analysis \\ of \\ electrical}




\subsection{Modal analysis}

The modal is the natural vibration characteristic of the mechanical structure. In recent years, the modal testing of structures has grown rapidly following developments in the hardware and software employed. In addition, its application is required as an auxiliary tool in design, structural modification, validation, model update and damage identification projects [6], [7].

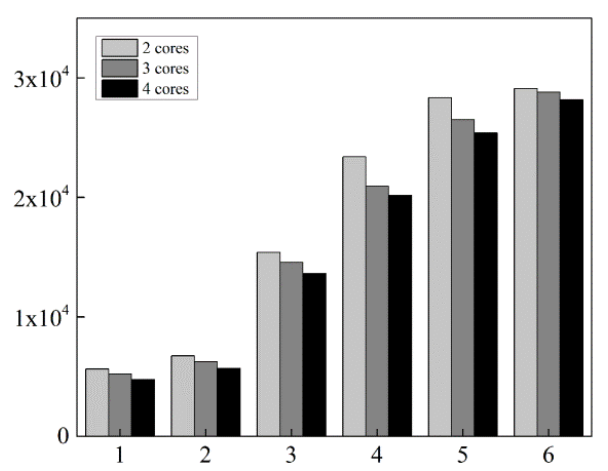

Figure 3. Comparison diagram of natural frequency for model I, II and III.

Import the models into Workbench ANSYS and set material properties shown in Table 1 respectively. The natural frequencies of models are obtained as indicated in Fig. 3.

Fig. 3 shows calculated natural frequencies for each model. The frequency response situations of the three models at the measurement points have clearly different natural frequencies. Analyze and conclude that, the natural frequency of the different orders increases with the increase of modal order, and the natural frequency of the same order decreases with the increase of contact cores. Therefore, the electrical connector with four cores has a better performance.

\subsection{Harmonic response analysis}

The harmonic response analysis is a time domain analysis method and therefore is of fundamental importance [8]. In the process of analysis, the steady-state of the structure is calculated only, and the transient vibration is not considered at the beginning of excited vibration. The acceleration load is used in this analysis.

According to the experiment condition of vibration stipulated in ANSI/EIA- -364-28E (electrical connector test method) and Test condition II , the frequency and accelerated speed are selected as $100 \mathrm{~Hz}$ and $98.1 \mathrm{~ms}^{-2}$, $300 \mathrm{~Hz}$ and $98.1 \mathrm{~ms}^{-2}, 500 \mathrm{~Hz}$ and $98.1 \mathrm{~ms}^{-2}$ respectively in the simulation. Such three sets of parameters are used to carry out harmonic response analysis on the models [9], [10].

Now, the correctness of the simulation result can be verified by the vibration formula:

$$
Z=A \cdot \sin (2 \pi f \cdot t+\theta)
$$

Second derivative of Equation (1) for time can be written as the form:

$$
a=-4 A \cdot \pi^{2} \cdot f^{2} \cdot \sin (2 \pi f \cdot t+\theta)
$$

where $Z, A, f, \theta$ and $a$ are vibration displacement, maximum value of displacement $Z$, vibration frequency, initial phase and the vibration acceleration.

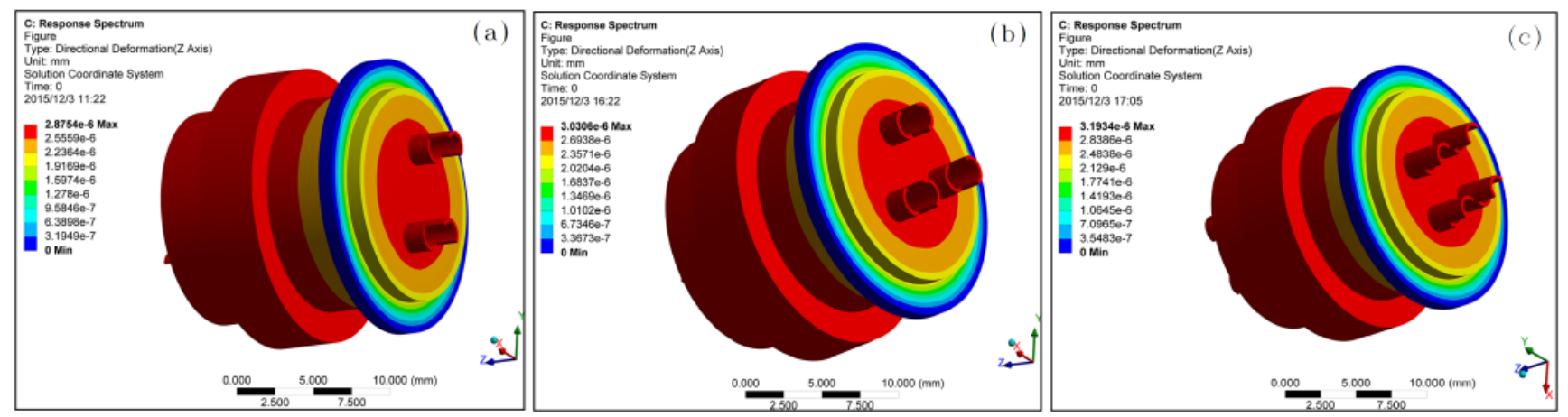

Figure 4. Deformation nephogram of harmonic response analysis ( $\mathrm{a}$ is for 2 cores, $\mathrm{b}$ is for 3 cores, $\mathrm{c}$ is for 4 cores; $\mathrm{a}=98.1 \mathrm{~ms}^{-2} ; \mathrm{f}=$ $100 \mathrm{~Hz})$. 
II presented as follow:

$$
4 A \cdot \pi^{2} \cdot f^{2}=98.1
$$

As can be seen, $A$ is inversely proportional to $f$. The vibration $Z$ will be small as substituting getting smaller amplitude affected by frequency's getting bigger to Equation (1). In modal analysis, the natural frequency and the maximum deformation of the electrical connector with the core number of 2, 3 and 4 are gradually reduced and gradually increased respectively, which is consistent with the results of ANSYS.

\section{Conclusion}

(1) Through steady-state analysis and transient temperature analysis, it is indicated that the heat dissipation increased gradually with the core number. The simulation results calculated by Fourier law coincide with the results of theoretical analysis that the electrical connector with 4 contact cores has the highest heat transfer rate and best heat dissipation performance. (2) By vibration analysis, it is concluded that with the increase of vibration frequency, the maximum deformation of the models in increasing. At the same frequency, the maximum deformation increased gradually with the number of cores.

\section{Acknowledgements}

This study was funded by the Fundamental Research Funds for the Central Universities (Grant No.N130303002), the Postdoctoral Science Foundation of
China (Grant No.2014M561243), the Scientific Research Foundation for the Returned Overseas Chinese Scholars, State Education Ministry (50-5), and the Doctoral Scientific Research Foundation of Liao Ning Province (Grant No.20141004).

\section{References}

1. Y. V. Murty, Ency. Mater: Sci. and Technol.: 2483-2494 (2001)

2. Y. Hayashi, T. Mizuki, H. Sone, IEEE Int. Symp. on EMC: 209-212 (2009)

3. Y. Hayashi, S. P. Wu, J. Fan H. Sone, IEEE Int. Symp. on EMC: $743-747$ (2010)

4. B. G. LeFevre, W. W. King, A. G. Hardee, A. W. Carlisle, K. B. Bradley, J. Lightw. Technol. Vol. 11, No. 4: 537-541 (1993)

5. Y. L. Zhou, N. Zeng, L. J. Xu, J. Stefan, J. Zhejiang Univ. Sci. A Vol. 8, No. 3: 384-392 (2007)

6. E. N. B. S. Júlio, C. A. S. Rebelo, D. A. S. G. Dias-da-Costa, Eng. Struct Vol. 7, No. 11: 3,468-3,477 (2012)

7. M. Lepidi, V. Gattulli, D. Foti, Eng. Struct Vol. 31, No. 7: 1,486-1,500 (2009)

8. L. Li, Y. J. Hu, X. L. Wang L. Lü, Mech. Syst. Signal Proc. Vol. 42, No. 1-2: 31-41 (2014)

9. D. L. Cronin, S. Adhikari, Eng. Mech. Vol. 125, No. 12: 1,372-1,379 (1999)

10. L. Li, Y. J. Hu, X. L. Wang, L. Ling, J. Finite Elem. Anal. Des. Vol. 72, No. 19: 21-34 (2013) 